\title{
A schematic sampling protocol for contaminant monitoring in raptors
}

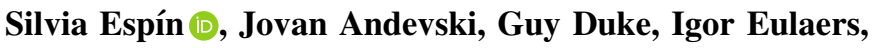 \\ Pilar Gómez-Ramírez, Gunnar Thor Hallgrimsson, Björn Helander, \\ Dorte Herzke, Veerle L. B. Jaspers, Oliver Krone, Rui Lourenço, \\ Pedro María-Mojica, Emma Martínez-López, Rafael Mateo, \\ Paola Movalli, Pablo Sánchez-Virosta, Richard F. Shore, \\ Christian Sonne, Nico W. van den Brink, Bert van Hattum, \\ Al Vrezec, Chris Wernham, Antonio J. García-Fernández
}

Received: 31 March 2020/Revised: 22 April 2020/Accepted: 22 April 2020/Published online: 12 May 2020

\begin{abstract}
Birds of prey, owls and falcons are widely used as sentinel species in raptor biomonitoring programmes. A major current challenge is to facilitate large-scale biomonitoring by coordinating contaminant monitoring activities and by building capacity across countries. This requires sharing, dissemination and adoption of best practices addressed by the Networking Programme Research and Monitoring for and with Raptors in Europe (EURAPMON) and now being advanced by the ongoing international COST Action European Raptor Biomonitoring Facility. The present perspective introduces a schematic sampling protocol for contaminant monitoring in raptors. We provide guidance on sample collection with a view to increasing sampling capacity across countries, ensuring appropriate quality of samples and facilitating harmonization of procedures to maximize the reliability, comparability and interoperability of data. The here presented protocol can be used by professionals and volunteers as a standard guide to ensure harmonised sampling methods for contaminant monitoring in raptors.
\end{abstract}

Keywords Best practices - Birds of prey - Falcons . Large-scale biomonitoring · Owls · Pan-European network

\section{INTRODUCTION}

Birds, and especially raptors (i.e. birds of prey, owls and falcons), have been widely used as sentinel species in biomonitoring programmes worldwide (Gómez-Ramírez et al. 2014; Espín et al. 2016). Such studies are used to

Electronic supplementary material The online version of this article (https://doi.org/10.1007/s13280-020-01341-9) contains supplementary material, which is available to authorized users. evaluate spatiotemporal trends in contaminant concentrations and related effects and can provide early warning of emerging contaminant problems. In addition, they may be used to track the success of regulatory directives designed to protect humans, wildlife and the wider environment from pesticides and industrial contaminants (e.g. Council Regulation 315/93/EEC; REACH EU Regulation; Stockholm Convention on POPs; Aarhus Protocol on POPs; POPs regulation EU No. 2019/1021).

Because chemicals regulation is harmonised within the European Union, a major current challenge is to improve large-scale (pan-European) biomonitoring. This can be addressed by coordinating Europe-wide contaminant monitoring in raptors and by building capacity across countries. This requires sharing, dissemination and adoption of best practices. This was addressed by the Research Networking Programme Research and Monitoring for and with Raptors in Europe (EURAPMON, 2010-2015), funded by the European Science Foundation (https://www. eurapmon.net/) and is now being further advanced by the ongoing international COST Action, European Raptor Biomonitoring Facility (ERBFacility, CA16224, 2017-2021) (https://erbfacility.eu/). Under ERBFacility, three inter-linked scientific arenas are cooperating, the 'analysis arena' on ecotoxicological analyses, the 'collections arena' on storing and cataloguing raptor samples, and the 'field arena' on gathering additional samples and contextual field data (Duke et al. 2018; Movalli et al. 2019). This pan-European network of ornithologists, veterinary scientists, raptor ecologists, ecotoxicologists and analytical chemists will enable a new generation of research on environmental biomonitoring using raptors. 


\section{TOWARDS HARMONISATION AND APPROPRIATE QUALITY OF SAMPLES FOR CONTAMINANT MONITORING}

In the EURAPMON programme it was identified that differences between studies in sampling and processing strategies for contaminant monitoring hampered direct comparison of study results and an integrated interpretation (Movalli et al. 2008). The use of appropriate sample containers and storage conditions was also identified as an essential step to avoid contamination of samples or degradation of the compound of interest, and information on this needed to be easily accessible to personnel collecting and sending samples to ecotoxicological laboratories. Although toxicology specialists have a deep understanding on these issues, other groups of professionals (e.g. field researchers) or volunteers (e.g. ringers) collecting samples need guidance that ensures appropriate collection of samples without compromising the analytical quality of the sample. Indeed, raptor population monitoring activities have the potential to enhance a widescale availability of raptor samples that are interlinked with key contextual data (e.g. breeding success, population trends, survival, diet, etc.), since some of the biological matrices needed for analysis (e.g. feathers, addled/deserted eggs, blood) are routinely collected as part of surveys of raptor breeding populations (Espín et al. 2016; Derlink et al. 2018). Consequently, it is essential to provide protocols on appropriate sampling methods for contaminant monitoring, for field ornithologists, personnel at museums and Wildlife Rehabilitation Centres, and other people involved in raptor sample collection.

A detailed best-practice sampling protocol was previously prepared by EURAPMON (Espín et al. 2014), as well as a publication of the potential widescale availability of raptor samples and the relative merits of each matrix type (Espín et al. 2016). However, through more recent meetings and workshops under ERBFacility involving researchers across 27 countries, the need to elaborate a protocol in a more schematic and clear format was identified. This schematic protocol should provide essential information on the practicalities of sampling and storage that were not earlier reported by Espín et al. 2014 (e.g. type of containers to conserve matrices, storage and transport conditions, and how these differ depending on the sample matrices and the contaminant to be analysed). Twentythree researchers involved in the three arenas of the ERBFacility COST Action and representing 11 countries (Denmark, Germany, Iceland, Norway, Portugal, Slovenia, Spain, Sweden, Switzerland, The Netherlands and United Kingdom), have participated in the preparation of this schematic sampling protocol based upon their expertise in sampling and contaminant monitoring in raptors.

The protocol presented in this perspective (see Electronic Supplementary Material) provides guidance on sample collection for contaminant monitoring in raptors with a view to increasing sampling capacity across countries and facilitating harmonization of procedures to maximize the reliability, comparability and interoperability of biomonitoring data. While the protocol has been prepared under a Europe COST Action, the guidance is applicable to raptor monitoring worldwide. The protocol is presented as Supplementary Material to this communication, and has been prepared following an easy-to-follow style, with hyperlinks to redirect the reader to the relevant information elsewhere in the protocol.

The schematic protocol starts with each matrix type, including sample types that are collected both during active sampling (samples taken from captured live birds and monitored nests) and passive monitoring (samples taken from dead birds and deserted nests) (Fig. 1). These sample types include whole blood, plasma, serum, deserted or addled eggs, feathers, preen oil, regurgitated pellets, prey remains, gastric content and internal tissues. The reader clicks on the sample type of interest and is redirected to the specific protocol for each matrix (e.g. see protocol for blood sampling in Fig. 2), which in turn offers further hyperlinks to additional and more detailed information. Some important general guidelines are also given regarding sampling and ethical permits, personal safety and wildlife health, animal welfare, labelling samples, and essential guidance to avoid contamination and to record basic data (date, location, etc.) in the sampling report. Moreover, new information is provided on the volume/mass of sample needed for contaminant monitoring, the most suitable container type to conserve the sample, and the necessary conditions required for transportation and storage.

Different sample matrices provide different information about exposure and effects and not all are suitable for biomonitoring (Espín et al. 2016). Thus, information on the type of contaminants and biomarkers most frequently analysed in the different matrices in live and dead birds is also shown. Photographs and links to web-based videos are also provided to illustrate the proper materials and methods needed for sample collection, taking measurements (such as measuring egg size, eggshell thickness, body fat tissue during necropsy, etc.) and identifying gonads and internal tissues.

We recommend the schematic protocol for use by professionals and volunteers as a standard guide to ensure harmonised sampling methods and appropriate quality of samples collected for contaminant monitoring in raptors. 
European Raptor

Biomonitoring Facility

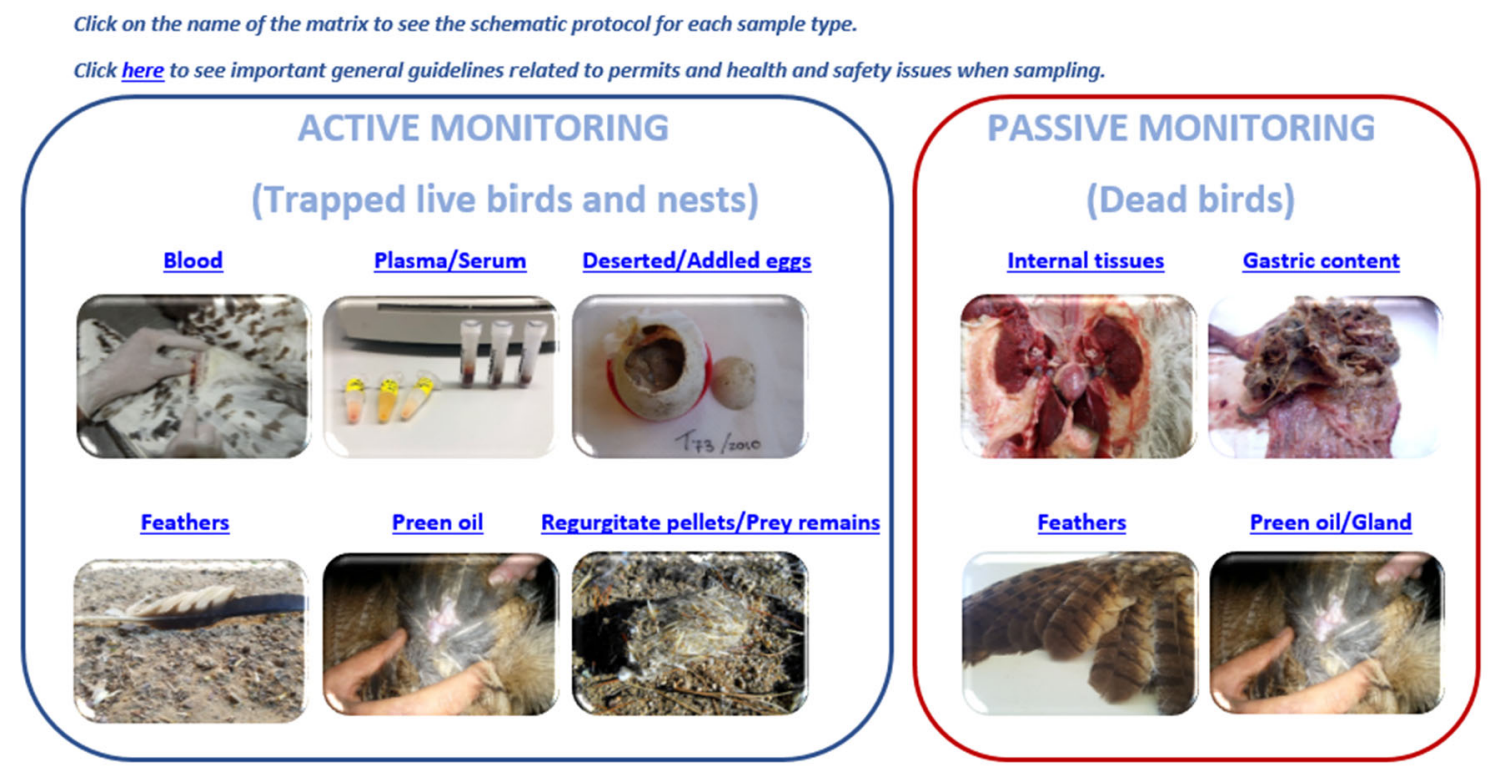

Click here to see Table 1. Volume/Mass of sample, type of container and transport conditions required for contaminant monitoring in different matrices Click here to see Figure 1. What can we measure in each sample type? (a. Active monitoring / b. Passive monitoring)

Fig. 1 Preview of the main menu of the schematic protocol (full protocol presented as Supplementary Material)

European Raptor

Biomonitoring Facility

\section{Schematic protocol for blood}

Click here to get additional information
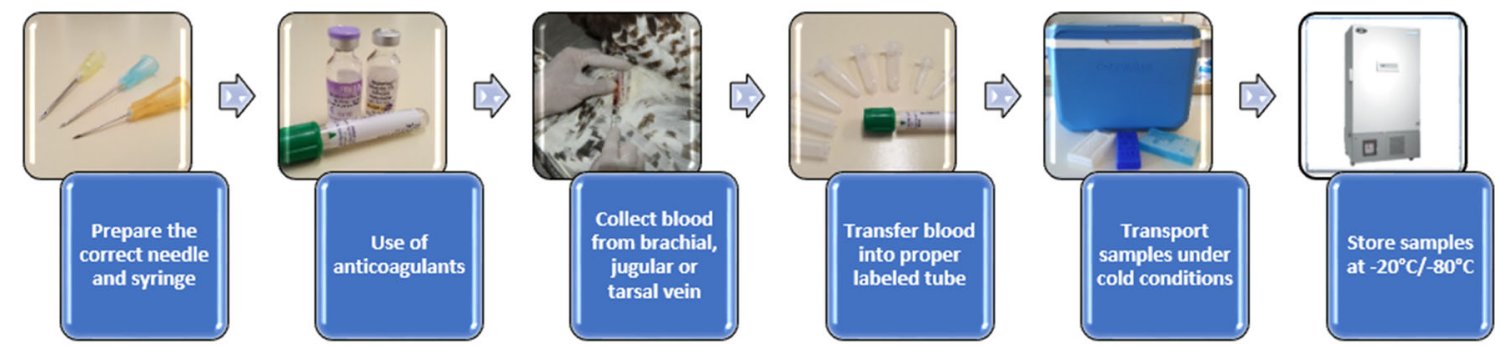

Click here to see video $\mathbf{B}$

Click here to see Table 1. Volume/Mass of sample, type of container and transport conditions required for contaminant monitoring in different matrices

Click here to see Figure 1. What can we measure in each sample type? (a. Active monitoring / b. Passive monitoring)

Fig. 2 Preview of the schematic protocol for blood sampling (full protocol presented as Supplementary Material)

Contaminant issues often occur across national and continental boundaries, and therefore require harmonised methods to study their occurrence, impact and any effect of legal or voluntary mitigation, whether of legacy, current or emerging contaminants. 
Acknowledgements European Raptor Biomonitoring Facility COST Action (CA16224) is supported by COST (European Cooperation in Science and Technology) and funded by the Horizon 2020 Framework Programme of the European Union. Silvia Espín is financially supported by Ministerio de Ciencia, Innovación y Universidades (Juan de la Cierva-Incorporación contract, IJCI-2017-34653).

Open Access This article is licensed under a Creative Commons Attribution 4.0 International License, which permits use, sharing, adaptation, distribution and reproduction in any medium or format, as long as you give appropriate credit to the original author(s) and the source, provide a link to the Creative Commons licence, and indicate if changes were made. The images or other third party material in this article are included in the article's Creative Commons licence, unless indicated otherwise in a credit line to the material. If material is not included in the article's Creative Commons licence and your intended use is not permitted by statutory regulation or exceeds the permitted use, you will need to obtain permission directly from the copyright holder. To view a copy of this licence, visit http://creativecommons.org/licenses/by/4.0/.

\section{REFERENCES}

Derlink, M., C. Wernham, I. Bertoncelj, A. Kovács, P. Saurola, G. Duke, P. Movalli, and A. Vrezec. 2018. A review of raptor and owl monitoring activity across Europe: Its implications for capacity building towards pan-European monitoring. Bird Study 65: S4-S20.

Duke, G., A. Vrezec, P. Movalli, I. Bertoncelj, and C. Wernham. 2018. Editorial. Bird Study 65: S1-S2.

Espín, S., A.J. García-Fernández, D. Herzke, R.F. Shore, B. van Hattum, E. Martínez López, M. Coeurdassier, I. Eulaers, et al. 2016. Tracking pan-continental trends in environmental contamination using sentinel raptors-What types of samples should we use? Ecotoxicology 25: 777-801.

Espín, S., A.J. García-Fernández, D. Herzke, R.F. Shore, B. van Hattum, E. Martínez López, M. Coeurdassier, I. Eulaers, et al. 2014. Sampling and contaminant monitoring protocol for raptors. Research Networking Programme-EURAPMON, Research and monitoring for and with raptors in Europe. www. eurapmon.net.

Gómez-Ramírez, P., R.F. Shore, N.W. van den Brink, B. van Hattum, J.O. Bustnes, G. Duke, C. Fritsch, A.J. García-Fernández, et al. 2014. The first inventory of existing raptor contaminant monitoring activities in Europe. Environment International 67: 12-21.

Movalli, P., G. Duke, and D. Osborn. 2008. Introduction to monitoring for and with raptors. Ambio 37: 395-396.

Movalli, P., G. Duke, G. Ramello, R. Dekker, A. Vrezec, R.F. Shore, A.J. García-Fernández, C. Wernham, et al. 2019. Progress on bringing together raptor collections in Europe for contaminant research and monitoring in relation to chemicals regulation. Environmental Science and Pollution Research 26: 20132-20136.

Publisher's Note Springer Nature remains neutral with regard to jurisdictional claims in published maps and institutional affiliations.

\section{AUTHOR BIOGRAPHIES}

Silvia Espín $(\bowtie)$ is a post-doctoral researcher at the University of Murcia. Her research interests include wildlife ecotoxicology, focusing on contaminant exposure and related effects on physiology, growth, reproduction and survival.
Address: Area of Toxicology, Faculty of Veterinary Medicine, University of Murcia, Campus Espinardo, 30100 Murcia, Spain. e-mail: silvia.espin@um.es

Jovan Andevski is a Programmes Manager and European Regional Coordinator of the Multi-species Action Plan to conserve AfricanEurasian Vultures (Vulture MsAP) at the Vulture Conservation Foundation. His interests focus on implementation of diverse vulture conservation and research activities at European level.

Address: Vulture Conservation Foundation, Wuhrstrasse 12, 8003

Zurich, Switzerland.

e-mail: j.andevski@4vultures.org

Guy Duke is Chair of the COST Action 'European Raptor Biomonitoring Facility' and is an Honorary Research Associate at the Environmental Change Institute, University of Oxford and a Fellow of the UK Centre for Ecology \& Hydrology. His interests focus on environmental research impact with policy and business.

Address: Environmental Change Institute, Oxford University Centre for the Environment, South Parks Road, Oxford OX1 3QY, UK. e-mail:guy.duke@skynet.be

Igor Eulaers is post-doctoral researcher at the Aarhus University, Department of Bioscience. His research interests include wildlife ecotoxicology, focusing on mechanistically elucidating species interactions and finding best practices in environmental monitoring of multiple stressors.

Address: Department of Bioscience, Faculty of Technical Sciences, Aarhus University, Frederiksborgvej 399, POBox 358, 4000 Roskilde, Denmark.

e-mail: igor.eulaers@outlook.com; ie@bios.au.dk

Pilar Gómez-Ramírez (Dr. med. vet.) is an Associate Professor at the University of Murcia. Her research interests include toxicology and biomonitoring contaminants in wildlife.

Address: Area of Toxicology, Faculty of Veterinary Medicine, University of Murcia, Campus Espinardo, 30100 Murcia, Spain. e-mail: pilargomez@um.es

Gunnar Thor Hallgrimsson is a Full Professor of Zoology at University of Iceland. His research interest includes mainly ecological studies on birds.

Address: Faculty of Life and Environmental Sciences, University of Iceland, Sturlugata 7, 102 Reykjavik, Iceland.

e-mail: gunnih@hi.is

Björn Helander is senior scientist at the Swedish Museum of Natural History, Environmental Research \& Monitoring. He is founder and leader of Project Sea Eagle/Sweden 1971-2013. His research interests include impact of environmental contaminants on reproduction and survival of apex predatory birds.

Address: Environmental Research and Monitoring, Swedish Museum of Natural History, Frescativägen 40, PO Box 50007, 10405 Stockholm, Sweden.

e-mail: Bjorn.Helander@nrm.se

Dorte Herzke is a senior scientist at the Norwegian Institute for Air research, NILU, in Norway. She is also active as an Associate Professor II at UiT, Institute for Arctic Marine Biology, with research interest in chemical pollution and ecotoxicology of apex predators and their prey.

Address: NILU - Norwegian Institute for Air Research, Hjalmar Johansen Gate 14, 9296 Tromsö, Norway.

e-mail: dorte.herzke@nilu.no 
Veerle L. B. Jaspers is a Full Professor at the Norwegian University of Science and Technology (NTNU). She is currently the head of the Environmental Toxicology Group at the department of Biology. Her research interests include the development of biomonitoring strategies for different chemical compounds and studying ecotoxicology with a focus on the interaction of pollution with multiple stressors on the individual and population level.

Address: Environmental Toxicology Group, Department of Biology, Norwegian University of Science and Technology, Høgskoleringen 5, NO-7491 Trondheim, Norway.

e-mail: veerle.jaspers@ntnu.no

Oliver Krone (Dr. med. vet.) is a senior scientist at the Leibniz Institute for Zoo and Wildlife Research Berlin, Dept. of Wildlife Diseases. He is leading the raptor study group and head of the toxicological and parasitological lab. His research interest is conservation medicine with a focus on apex predators and their prey.

Address: Department of Wildlife Diseases, Leibniz Institut for Zoo and Wildlife Research, Alfred-Kowalke-Str. 17, 10315 Berlin, Germany.

e-mail:KRONE@izw-berlin.de

Rui Lourenço is a researcher at the University of Évora, Portugal. His research interests include ecology, ecotoxicology, and conservation of raptors.

Address: MED - Mediterranean Institute for Agriculture, Environment and Development, LabOr, IIFA, Univ. Évora, Pólo da Mitra, Ap. 94, 7006-554 Évora, Portugal.

e-mail: lourenco@uevora.pt

Pedro María-Mojica (Dr. med. vet.) is Veterinarian in the Wildlife Rehabilitation Centre "Santa Faz" in Alicante and Part Time Lecturer at the University of Murcia. His research interests include wildlife forensic medicine and wildlife ecotoxicology, evaluating exposure and effects of contaminants.

Address: Area of Toxicology, Faculty of Veterinary Medicine, University of Murcia, Campus Espinardo, 30100 Murcia, Spain.

Address: Santa Faz" Wildlife Rehabilitation Centre, Alicante, Generalitat Valenciana, Spain.

e-mail: pmmojica@um.es

Emma Martínez-López (Dr. med. vet.) is an Associate Professor at the University of Murcia. Her research interest includes the use of wild animals as sentinels of environmental pollution and biomarkers of exposure and effects to contaminants and other chemicals.

Address: Area of Toxicology, Faculty of Veterinary Medicine, University of Murcia, Campus Espinardo, 30100 Murcia, Spain. e-mail: emmaml@um.es

Rafael Mateo is an Associate Professor at the University of CastillaLa Mancha (UCLM), and Researcher at the Institute for Game and Wildlife Research (IREC). His research interests include wildlife ecotoxicology and ecophysiology.

Address: Instituto de Investigación en Recursos Cinegéticos (IRECCSIC, UCLMJCCM), Ronda de Toledo 12, 13005 Ciudad Real, Spain.

e-mail: Rafael.Mateo@uclm.es

Paola Movalli is Ecotoxicologist at the Naturalis Biodiversity Center. She is a work package leader of the COST Action 'European Raptor Biomonitoring Facility'. Her research interests include contaminants in raptors and other apex predators.

Address: Naturalis Biodiversity Center, PO Box 9517, 2300 RA

Leiden, The Netherlands.

e-mail: paola.movalli@naturalis.nl
Pablo Sánchez-Virosta is a post-doctoral wildlife toxicologist at the University of Murcia. His research interests include ecotoxicology, evaluating exposure and effects of contaminants in wildlife.

Address: Area of Toxicology, Faculty of Veterinary Medicine, University of Murcia, Campus Espinardo, 30100 Murcia, Spain. e-mail: pablo.s.v@um.es

Richard F. Shore is the Science Area Head for Pollution at the UK Centre for Ecology \& Hydrology (http://www.ceh.ac.uk/staff/richardshore) and an Honorary Professor at Lancaster University. $\mathrm{He}$ is a work package leader of the COST Action 'European Raptor Biomonitoring Facility'. His research centres on the exposure and effects of pollutants, biocides and pesticides in wild birds and mammals and he leads the UK's Predatory Bird Monitoring Scheme (https://pbms.ceh.ac.uk/).

Address: UK Centre for Ecology \& Hydrology, Lancaster Environment Centre, Library Avenue, Bailrigg, Lancaster LA1 4AP, UK. e-mail: rfs@ceh.ac.uk

Christian Sonne is a Full Professor at Aarhus University. His research interests include wildlife population health, ecotoxicology and One Health.

Address: Department of Bioscience, Faculty of Technical Sciences, Aarhus University, Frederiksborgvej 399, POBox 358, 4000 Roskilde, Denmark.

e-mail: cs@bios.au.dk

Nico W. van den Brink is Associate Professor at Wageningen University, sub-department of Toxicology. His research interests include wildlife toxicology, focusing on mechanistically elucidating modes of toxicity on e.g. adverse behavioural endpoints and modulation of the immune system by chemicals.

Address: Sub-Division of Toxicology, Wageningen University, Box 8000, 6700 EA Wageningen, The Netherlands.

e-mail: nico.vandenbrink@wur.nl

Bert van Hattum (Dr.) is senior scientist (retired, visiting fellow) at the VU University Amsterdam, Department of Environment and Health. His research interests include biomonitoring of contaminants, wildlife ecotoxicology, chemical fate modelling and risk assessment of persistent contaminants.

Address: Dep. Environment and Health, Faculty of Science, VU University Amsterdam, De Boelelaan 1085, 1081 HV Amsterdam, The Netherlands.

e-mail: bertvanhattum@gmail.com

Al Vrezec is Vice-Chair of the COST Action 'European Raptor Biomonitoring Facility' and is a Senior Scientific Collaborator at National Institute of Biology and Museum Advisor responsible for bird collection at Slovenian Museum of Natural History. His research interests include raptor ecology, ecosystem function, conservation biology as well as museum ornithology.

Address: Department of Organisms and Ecosystems Research, National Institute of Biology, Večna pot 111, 1000 Ljubljana, Slovenia. Address: Slovenian Museum of Natural History, Prešernova 20, 1000 Ljubljana, Slovenia.

e-mail: al.vrezec@nib.si

Chris Wernham (Dr.) is Associate Director of Country Offices at the British Trust for Ornithology (Scotland). She is a work package leader of the COST Action 'European Raptor Biomonitoring Facility'. Her research interests include wildlife monitoring via citizen science approaches, raptor monitoring, approaches to involving the public in environmental monitoring, and stakeholder engagement in humanwildlife conflict situations. 
Address: British Trust for Ornithology (Scotland), Unit 15 Beta Centre, Stirling University, Innovation Park, Stirling FK9 4NF, Scotland.

e-mail: chris.wernham@bto.org

Antonio J. García-Fernández is Full Professor at the University of Murcia. He is Principal Investigator of the Toxicology Group (University of Murcia, UM) and Toxicology and Risk Assessment Group (IMIB), Head of the Forensic Toxicology Unit and the
Toxicology and Forensic Veterinary Medicine Service at the UM (http://www.sertoxmur.com). He is a work package leader of the COST Action 'European Raptor Biomonitoring Facility'. His research interests include wildlife ecotoxicology, focusing on the exposure and effects of contaminants in the context of One Health. Address: Area of Toxicology, Faculty of Veterinary Medicine, University of Murcia, Campus Espinardo, 30100 Murcia, Spain. e-mail: ajgf@um.es 